\title{
One-Pot Palladium-Catalyzed Cross-Coupling Reaction of Aryl Iodides with Stannylarsanes and Stannylstibanes
}

Mariana Bonaterra, Sandra E. Martín* and Roberto A. Rossi*

\section{Experimental Section}

General Methods: Gas chromatographic analyses were performed on a Hewlett-Packard 5890 Series II instrument with a flame ionisation detector, a Hewlett-Packard 3396 Series III integrator, an one of the following columns: HP1 $5 \mathrm{~m}$ x $0.53 \mathrm{~mm}$ column, and a DB-1, $30 \mathrm{~m} \mathrm{x}$ $0.17 \mathrm{~mm}$ column. ${ }^{1} \mathrm{H}$ NMR $(200.13 \mathrm{MHz})$ and ${ }^{13} \mathrm{C}$ NMR $(50.32 \mathrm{MHz})$ were conducted on a Bruker AC 200 spectrometer in $\mathrm{CDCl}_{3}$ as solvent. GC/MS analyses were carried out on a Shimadzu GC/MS QP 5050 spectrometer equipped with a DB-5, $30 \mathrm{~m}$ x $0.18 \mathrm{~mm}$ ID column. Materials: $\mathrm{Ph}_{3} \mathrm{As}, \mathrm{Ph}_{3} \mathrm{Sb}, n$ - $\mathrm{Bu}_{3} \mathrm{SnCl}$, the palladium catalysts $\left(\mathrm{PPh}_{3}\right)_{2} \mathrm{PdCl}_{2}$ and $\left(\mathrm{PPh}_{3}\right)_{4} \mathrm{Pd}$ and the iodoarenes were commercially available and used as received from the supplier. Toluene and THF were distilled under nitrogen from sodium/benzophenone.

General Procedure for Preparation of Aryldiphenylarsanes and Stibanes from Aryl Iodides. The following procedure is representative of all these reactions. Ammonia $(300 \mathrm{~mL})$, previously dried over $\mathrm{Na}$ metal, was distilled into a $500-\mathrm{mL}$ three-neck round-bottom flask equipped with a cold finger condenser and a magnetic stirrer. To the ammonia were added $\mathrm{Ph}_{3}$ As $(1 \mathrm{mmol})$ and then $\mathrm{Na}$ metal $(2 \mathrm{mmol})$ in small pieces. The addition of $\mathrm{Na}$ metal continued until the blue solution from solvated electrons in excess remained for 20 minutes before it became orange-brown and no more solid was present. To this solution was added $t$ $\mathrm{BuOH}$ to decolorize and then one additional mmol to neutralize the amide ions formed. After that, $\mathrm{Ph}_{2} \mathrm{As}$ anion was ready for use (clear orange solution). $n-\mathrm{Bu}_{3} \mathrm{SnCl}$ (1 mmol) was added slowly, the mixture was stirred for 5 minutes and then ammonia was allowed to evaporate. Evaporation left a solid white residue, which was dissolved in dry toluene $(30 \mathrm{~mL})$. In the Schlenck tube which contained $\left(\mathrm{PPh}_{3}\right)_{2} \mathrm{PdCl}_{2}(0.015 \mathrm{mmol})$ and which was evacuated and filled with nitrogen three times, the above solution was introduced via canula and syringe. Then 1-iodonaphtalene $(0.8 \mathrm{mmol})$ and toluene $(5 \mathrm{~mL})$ were added. When the $n$ - $\mathrm{Bu}_{3} \mathrm{SnAsPh}_{2}$ solution was introduced, the reaction mixture turned deep brown. The reaction mixture was heated for 24 hours in an oil bath at $80^{\circ} \mathrm{C}$. To the cool reaction mixture, water was added and then extracted three times with dichloromethane $(30 \mathrm{~mL}$ each). After drying with anhydrous $\mathrm{MgSO}_{4}$, the products were quantified by GLC using the internal standard method. Naphthalen-1-yl-diphenyl-arsane was purified by silica-gel column chromatography (hexanes-ethyl acetate) to give a white solid $\mathrm{mp} 105-106^{\circ} \mathrm{C}$ (lit. ${ }^{20 \mathrm{a}} \mathrm{mp} 105.5-106.5^{\circ} \mathrm{C}$ ). ${ }^{1} \mathrm{H}$ NMR and ${ }^{13} \mathrm{C}$ NMR data of the products are shown below. 

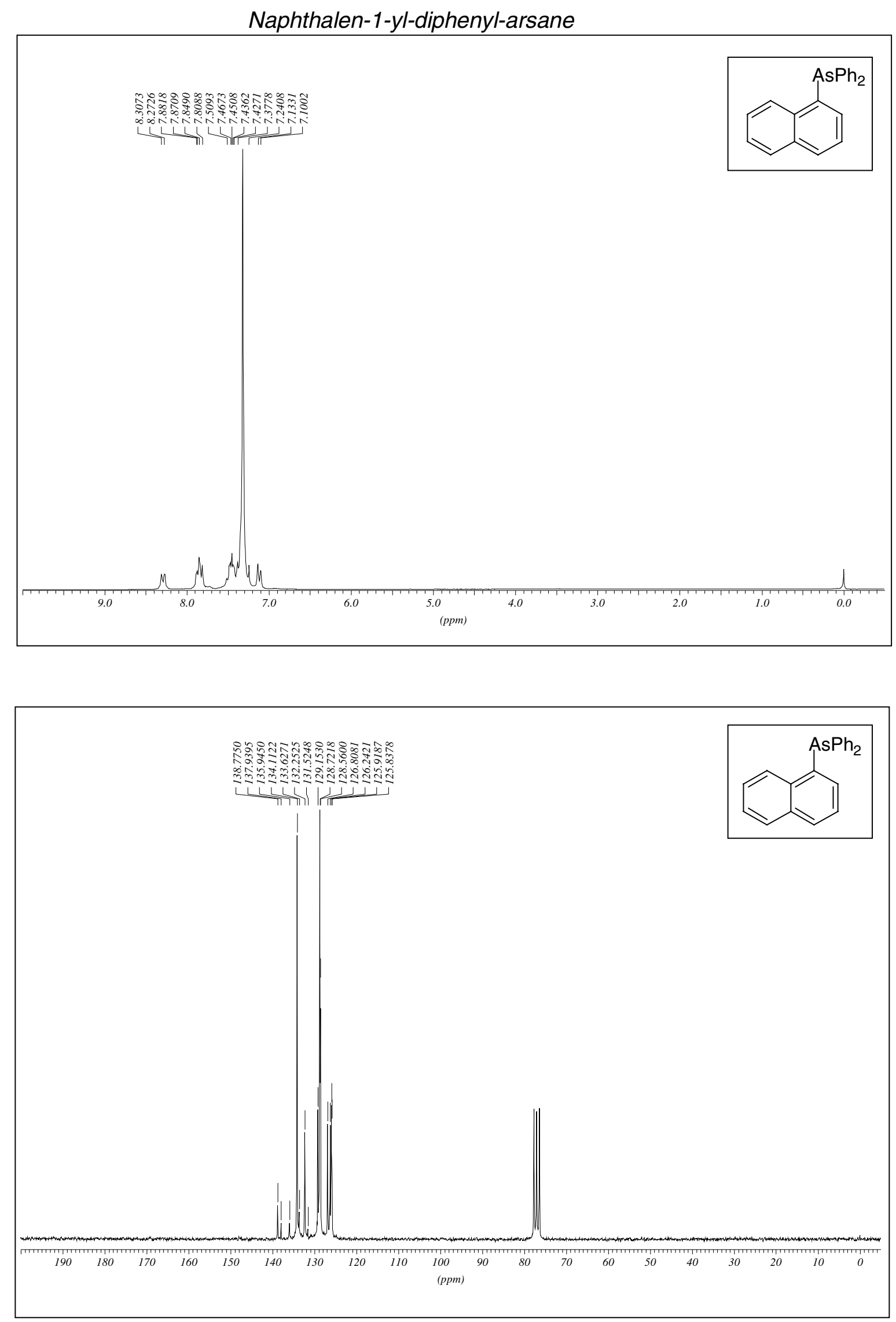

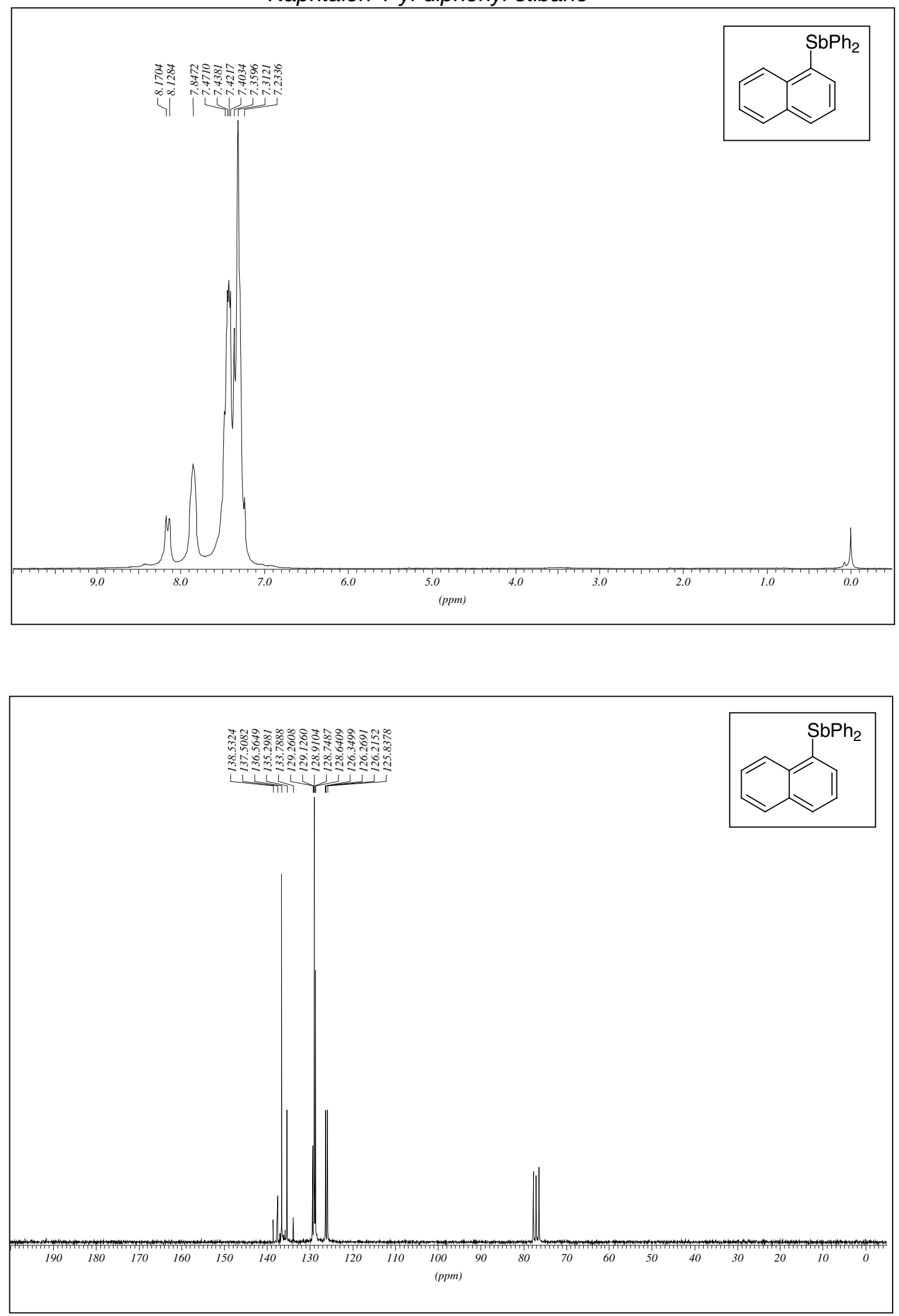
(4-Methoxyphenyl)diphenyl-arsane
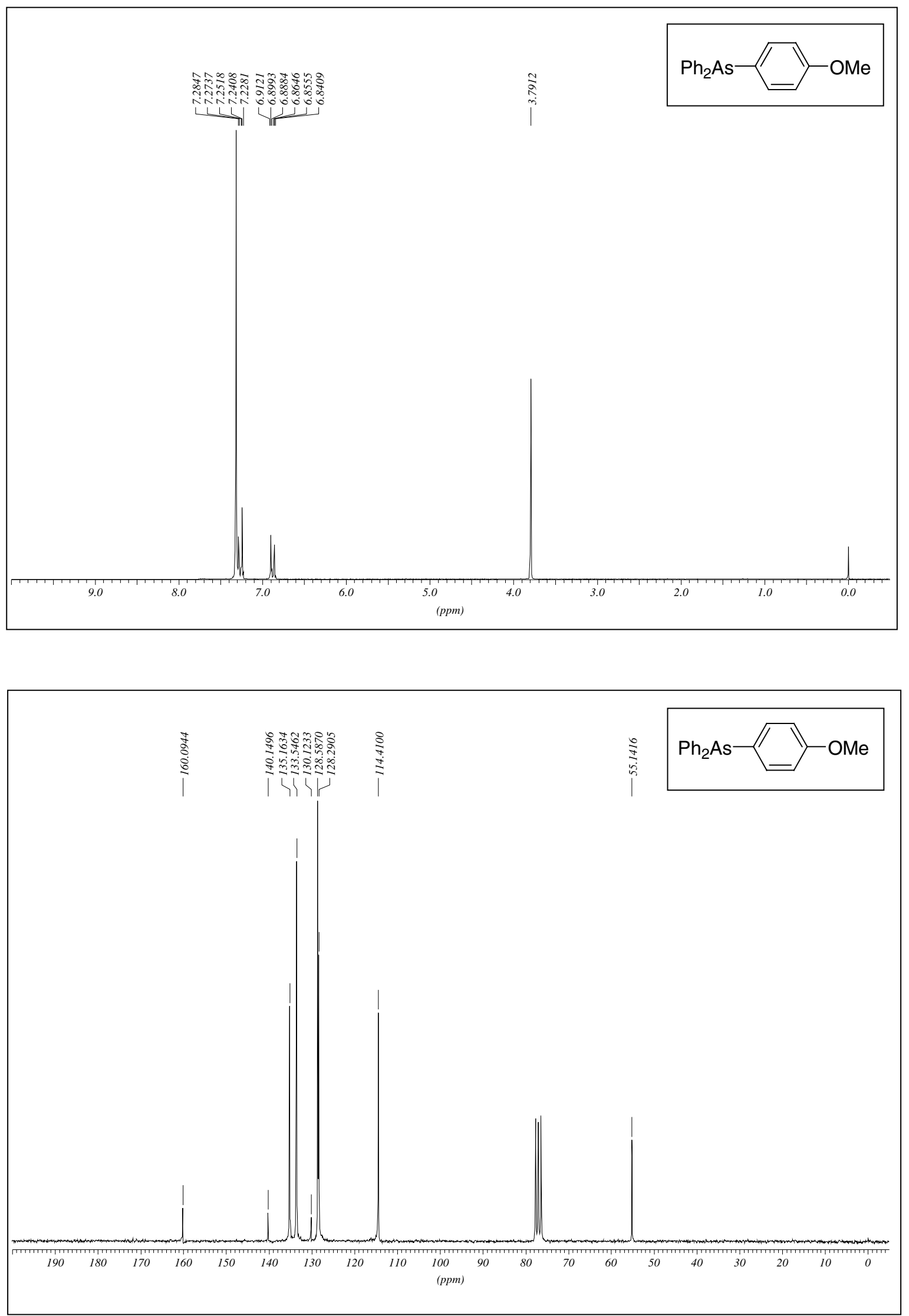


\section{(4-Chlorophenyl)diphenyl-arsane}
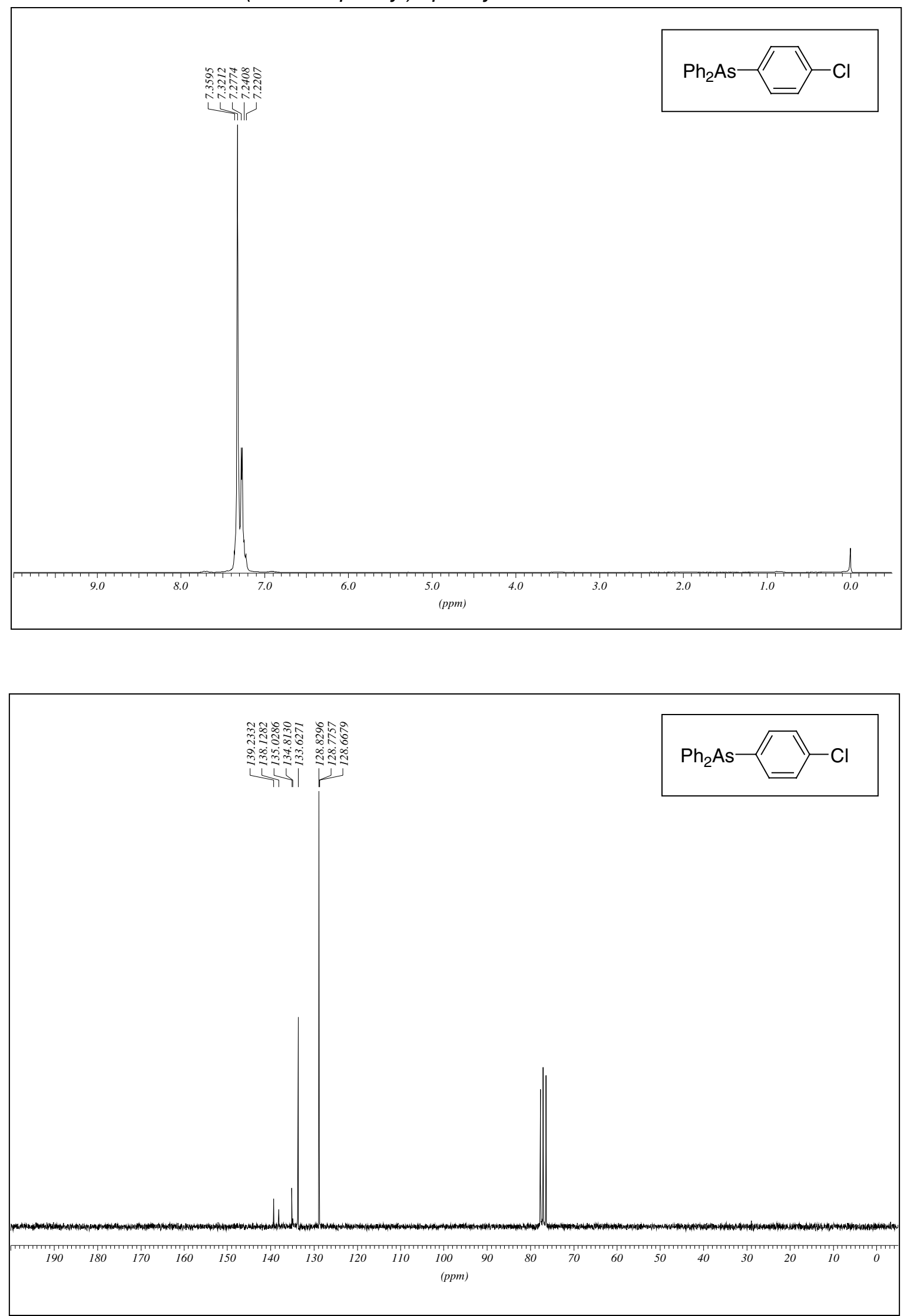
(4-Methoxyphenyl)diphenyl-stibane
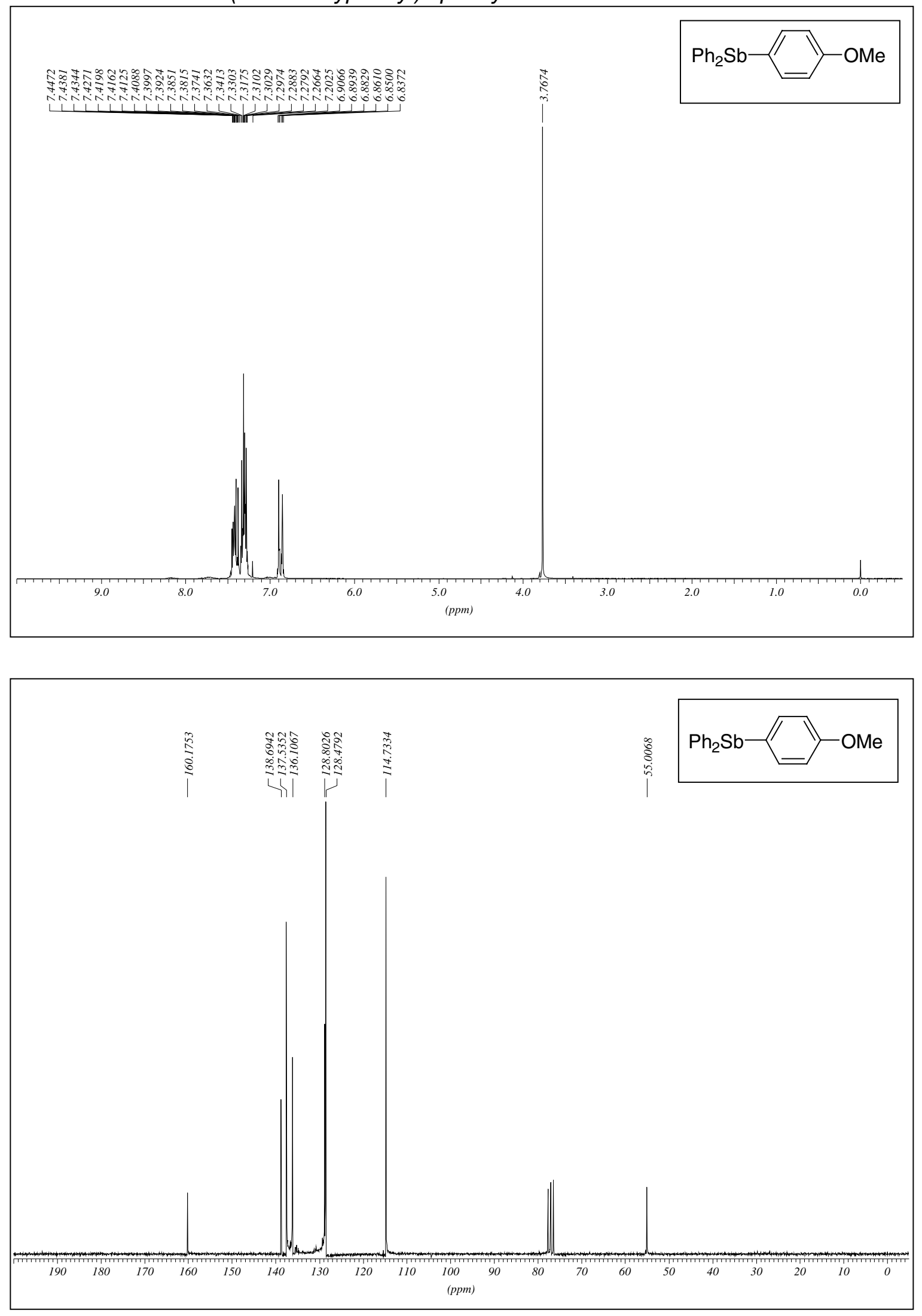
(4-Chlorophenyl)diphenyl-stibane
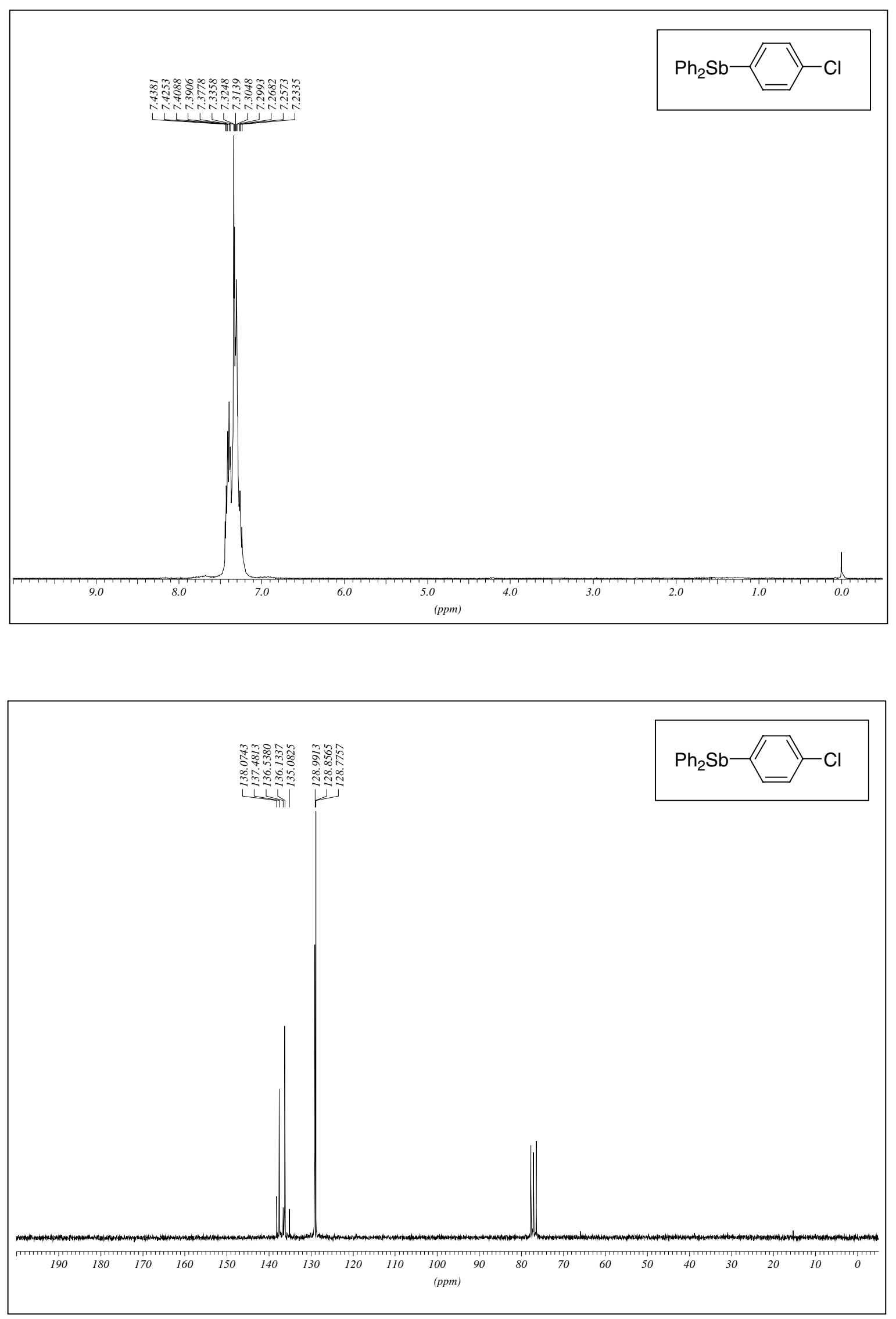